\title{
Discrete element simulation of internal stress in SiCp/aluminum matrix composite prepared by pressureless infiltration
}

\author{
Bai Liu *, Xiaohong Yang, Zhenyu Zhao \\ Shenzhem Institute of Information Technology, Shenzhen, 518172, P.R. CHINA \\ "Corresponding Author: e-mail: (Liu Bai) liub@sziit.edu.cn, co-author's e-mail: Yang Xiaohong (yangxh@ sziit.edu.cn), \\ co-author's e-mail: Zhao Zhenyu (zhaozy@sziit.edu.cn)
}

\begin{abstract}
$\mathrm{SiCp} / \mathrm{Al}-\mathrm{Mg}-\mathrm{Si}$ matrix composite was prepared by pressureless Infiltration Process. By discrete element method, microcosmic two-dimensional numerical model of $\mathrm{SiCp} / \mathrm{Al}$ matrix composites was established and the simulation of the size and distribution of micro-contact pressure and tension was performed from small load to big load until destruction. The results showed that the contact pressure appears the partial focus phenomenon, while the distribution of the contact tension tends to increase. When the calculation loop reaches 170,000 time steps, all the focus areas of contact pressure almost connected, but the contact tension is almost unchanged. At this time, the material closes to destruction. When the calculation loop reaches 210,000 time steps, the contact pressure tends to uniformity, but the distribution of contact tension becomes sparser. The contacts between the discrete units are approximately scattered and the contact tension is close to zero and the contact pressure is evenly even-distributed.
\end{abstract}

Keywords: Aluminum-matrix Composite, SiC, Discrete Element Simulation, Internal Stress

DOI: http://dx.doi.org/10.4314/ijest.v8i4.1

\section{Introduction}

Elastic modulus, high temperature strength, fatigue strength, and the mechanical properties of the alloy (see Liu and Liu, 2013; Liu et al., 2014) can be significantly enhanced by adding $\mathrm{SiC}_{\mathrm{p}}$ ( $\mathrm{p}$ indicates particles) into the $\mathrm{Al}$ alloy. Therefore $\mathrm{SiC} / \mathrm{Al}$ composite material has a broad application prospects, such as automobile brake disk, engine piston and gear. In the metal matrix composite materials, their morphology, microstructure, interface bonding condition have a very important effect on the load transfer, microstress and strain distribution, strengthen mechanisms and overall performance and so on and play a key role in influencing the performances of matrix and reinforcement and forming overall performance (Zhao et al., 2006; Hu et al., 1998; Xi-Ya, 2004; Zhang et al., 2001). The Discrete Element Method (DEM) is a numerical method used for solving microscopic mechanical behaviors of granular materials and has the advantage of being able to analyze the interactions in the materials because the deformation is a discontinuous, non-uniform and nonlinear phenomenon. Comparison of the numerical simulation of microstructures and properties of composite materials between the discrete element method developed from molecular dynamics and the finite element method led to the conclusion that the discrete element method has obvious advantages. It can directly describe the micro-structural characteristics within composite materials, thus, it is an ideal choice for micro-analysis of the structural characteristics of composite materials.

\section{Materials and microstructure}

\subsection{Preparation of materials}

The raw materials used in the experiment are as the follows: 
Matrix alloys: high purity aluminum (99.99\%), high-purity magnesium (99.9\%) and Al-Si alloys (Si content is about 20\%). The specified components were melt after calculating the proportion of the each ingredients, obtaining the Al-Mg-Si $-\mathrm{Re}(\mathrm{Rare}$ Earth Components) Department of the new cast aluminum alloy with optimized components. The smelting process started with melting pure aluminum and $\mathrm{Al}-\mathrm{Si}$ alloy, followed by adding pure magnesium with constant stirring. Then heating was provided to reach $720{ }^{\circ} \mathrm{C}-730{ }^{\circ} \mathrm{C}$. Hexachloroethane was added to get rid of gas. The melted mixture was put aside, slaged off and finally formed the Al-Mg-Si alloy ingot. Reinforcement: green silicon carbide powder (F220). The average diameter of SiC ceramic particles with cusp-shape was about $63 \mu \mathrm{m}$ (shown as Figure 1) and its basic performance was indicated in Table 1.

Table 1. Properties of $\mathrm{SiC}$ particle

\begin{tabular}{|l|c|c|c|c|c|}
\hline Crystal Type & Density $\left(\mathrm{g} / \mathrm{cm}^{3}\right)$ & Strength $(\mathrm{MPa})$ & $\begin{array}{l}\text { Modulus } \\
(\mathrm{GPa})\end{array}$ & $\begin{array}{l}\text { Melting } \\
\text { temperature }\left({ }^{\circ} \mathrm{C}\right)\end{array}$ & $\begin{array}{l}\text { Expansion coefficient } \\
\left(\mathrm{x} 10-6 /{ }^{\circ} \mathrm{C}\right)\end{array}$ \\
\hline$\alpha$-SiC & 3.2 & 500 & 450 & 2700 & 4.0 \\
\hline
\end{tabular}

Such an Al-Mg-Si-Re system of new cast aluminum alloy is used as the dedicated matrix alloy for a non-pressure infiltration. Firstly, silicon carbide particles were compact with a prefabricated part and a shaking table. Then it was kept in $180^{\circ} \mathrm{C}$ oven for $2 \sim 5$ hours. The matrix and alloy, together with the prefabricated part, were placed into the home-made non-pressure infiltration (work space size is $450 \mathrm{~mm} \times 500 \mathrm{~mm}$ ) special process equipment. At last infiltration was done around $800^{\circ} \mathrm{C}$ under the protection of nitrogen atmosphere.

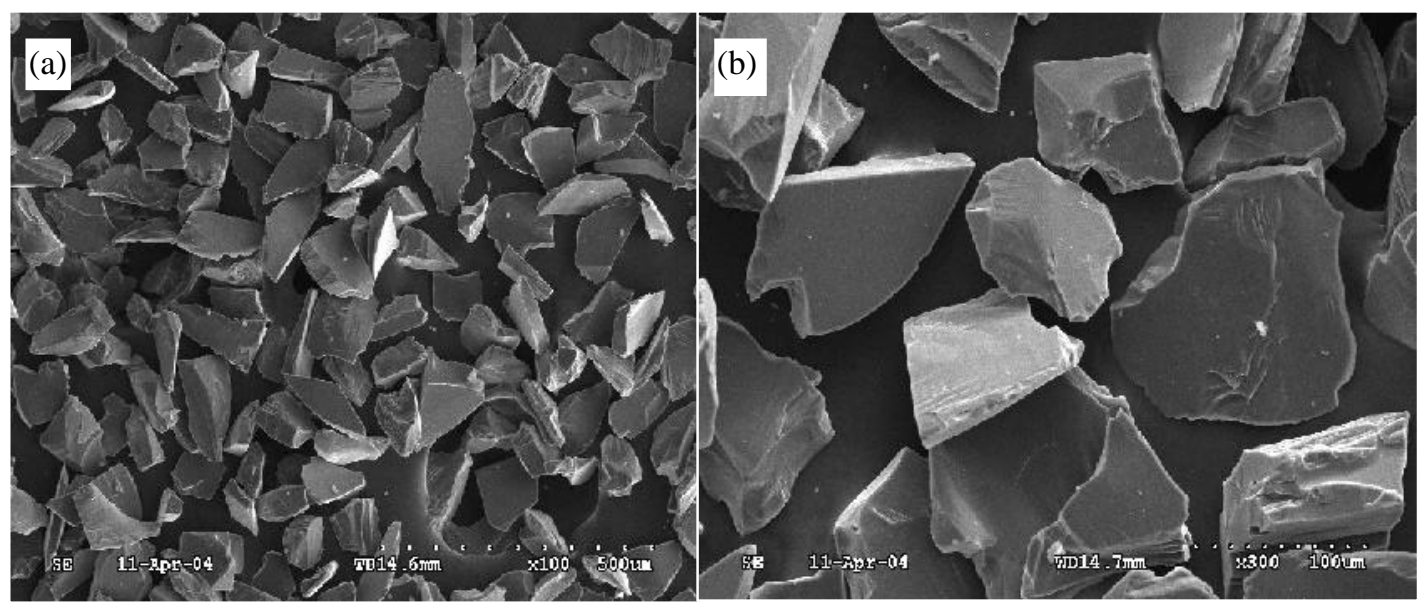

Fig.1 SEM photograph of SiC particles

\subsection{Microstructure of the composite}

After SiC/Al-matrix composite specimens prepared by pressureless infiltration were ground, ultrasonic treated and alcohol washed, observation of the microstructure was carried out by the DMRA/E-type optical microscope, shown as Figure 2.

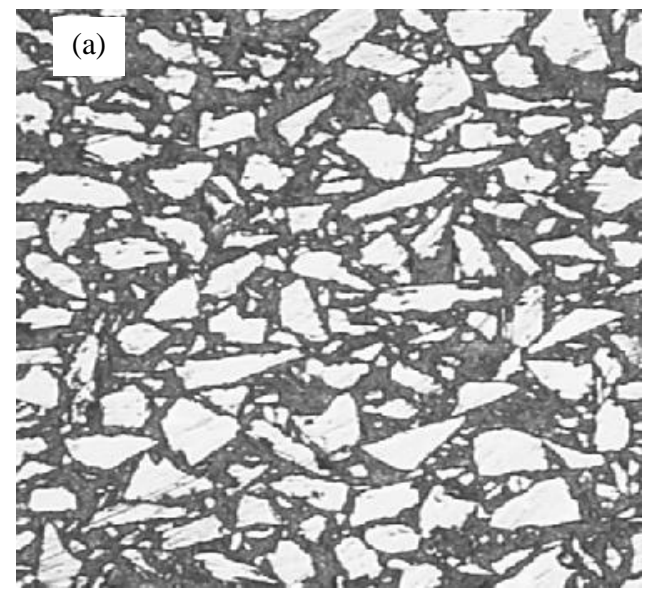

Middle-Multiple (polishing state)

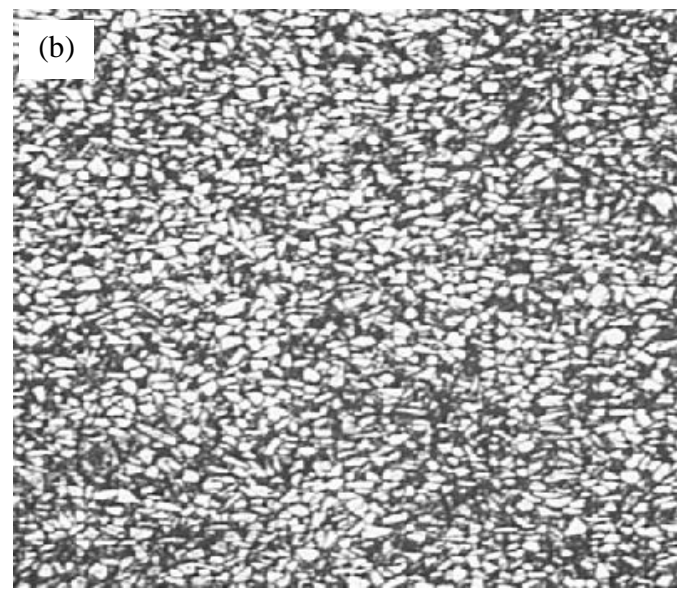

Low-Multiple (polishing state)

Figure 2. Optical photograph of SiC/Al-matrix composite 
As can be seen from the metallographic photos, $\mathrm{SiC}$ particles were polygons with edge angles and evenly distributed in the aluminum alloy matrix. $\mathrm{SiC}$ particles appeared dark gray and aluminum alloy matrix are white (Figures $2 \mathrm{a}$ and $\mathrm{b}$ ), while after polishing, $\mathrm{SiC}$ particles were light-colored and aluminum alloy matrix were gray. From the figure, we can see that infiltration was full and there were not large-size micro-defects. Because there was a melting process in the course of pressureless infiltration process, the process is a metallurgical process. Therefore, compared with the physical process of powder metallurgy, the probability of defects produced is greatly reduced. From Figure $2 b$, we can see that there are spottedstate precipitates in aluminum alloy matrix, which are eutectic precipitate Si phase in the Al matrix showing small light gray block (Chong et al., 2013; Chen et al., 2005; Liu et al., 2011).

In general, the composite material prepared by pressureless infiltration has a uniform distribution of particles, full infiltration of matrix metals (alloy), fewer defects, well bonded interface. From Figure 3, we can see that there are some small pores in a crosssection of $\mathrm{SiC}$ particles, which appeared in the $\mathrm{SiC}$ particles preparation process.

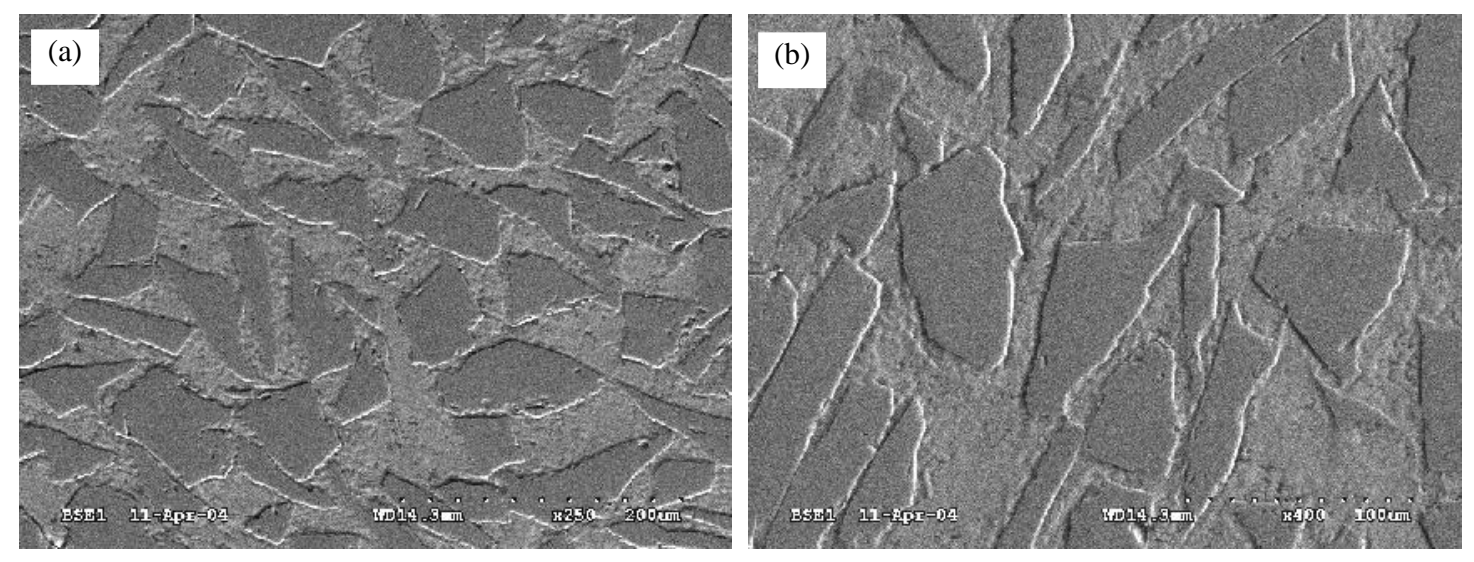

Figure 3. SEM photograph of SiC/Al-matrix composite

$\mathrm{SiC}$ ceramic large particles grow up from smaller particle crystallization, so grains can not fully grow up during crystallization, which leads to form cracks among grains, namely, the macro-view of pits (see additional information in Liu et al., 2013). As the size of $\mathrm{SiC}$ ceramic particles used in the experiment was up to $63 \mathrm{~m}$, so the pits were relatively clear. From the high resolution image we can see that interface bonding is in good condition, the infiltration of molten aluminum is full and there is no significant chemical reaction.

\section{Discrete element simulation of internal stresses in SiC/Al-matrix composite microstructure}

\subsection{Discrete element model for SiC/Al-matrix composite microstructure}

For the application of $\mathrm{SiC} / \mathrm{Al}$ composite materials in practical engineering, although the two-dimensional discrete element model has certain deviation in the analysis of the nature three-dimensional problem, combining the conditions of the present study with the basic principles of discrete element, the establishment and adoption of two-dimensional discrete element microstructure model is reasonable. In order to describe the complex reaction behavior of composite materials under certain boundary conditions form the micro-level view, they must be discrete to describe its reaction behavior by some micro-view of the parameters. After microstructure discretization of SiC/Al composite, discrete units composed of discrete structures are mutually independent and comply with its own constitutive relation and motion law. For the discretization of material structure from micro-level view and the establishment of micro-structure model, there is the problem of similar degree of the construction between numerical model and actual materials. Therefore, computer image processing techniques and fractal geometry has been applied to the microstructure analysis of composites (You, 2003; Djordjevic, 2003; Wang and Qin, 2007). In this study, the following discretization program is used:

Firstly, obtain the geometric parameters required for numerical simulation, including specimen scale, SiC particle grading, content and void ratio of $\mathrm{Al}$ alloys. Secondly, the whole material area was divided into $\mathrm{SiC}$ particles region, $\mathrm{Al}$ alloy region and gap fields. Then both the $\mathrm{SiC}$ particles region and the Al alloy region were further divided into smaller discrete units. The following steps were used to complete the region division of the material:

1. Regularly generate discrete units throughout the whole materials, shown in Figure 4.

2. Randomly generate different shapes of $\mathrm{SiC}$ particles, the corresponding location of $\mathrm{SiC}$ particles and the discrete units at the position, shown in Figure 5.

3. Give the discrete elements in the geometric space covered by the $\mathrm{SiC}$ particles the physical parameters of $\mathrm{SiC}$ particles, accordingly, give the discrete elements outside $\mathrm{SiC}$ particles the physical parameters of $\mathrm{Al}$ alloy and give the discrete elements at the contact surface of $\mathrm{Al}$ alloy and $\mathrm{SiC}$ particle the contact surface bonded characteristics. 
4. Make program files in accordance with program file format of discrete element software PFC ${ }^{2 \mathrm{D}}$ (Particle Flow Code in 2 Dimensions V.4.0, Itasca Consulting Ltd.) and generate PFC $^{2 \mathrm{D}}$ computational model.

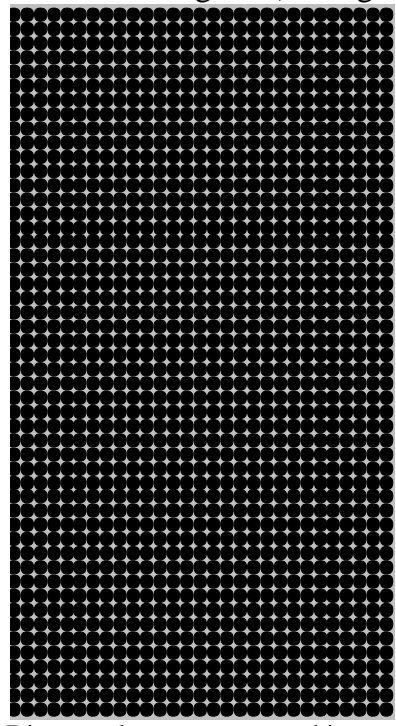

Figure 4. Discrete elements generated in material zone

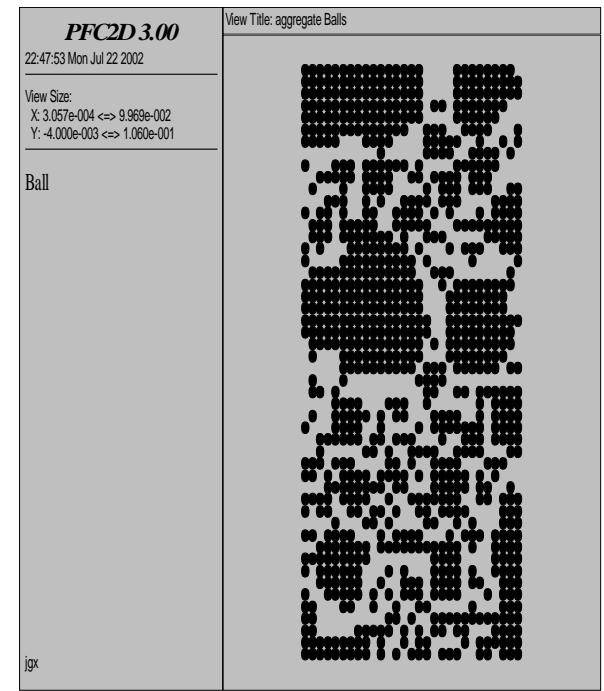

Figure 5. Randomly generated $\mathrm{SiC}$ particle discrete elements

\section{Simulation of the micro-properties of SiC/Al-matrix composite}

\subsection{Parameter values for numerical simulation}

Sample scale: the Length is $10 \mathrm{~cm}$, the width is $8 \mathrm{~cm}$.

The grain radius of discrete element: there are 7979 discrete units regularly generated, the unit grain radius is $0.5 \mathrm{~mm}$.

The parameters of $\mathrm{SiC}$ particles generated: the particle radius range is from $0.5 \mathrm{~mm}$ to $1.0 \mathrm{~mm}$, the porosity is 0.33 .

The microscopic parameters are selected as the follows:

The performance parameters of SiC particle unit: the Normal stiffness is 50Gpa, the tangential stiffness is 50Gpa, the normal and tangential bond strengths are $8000 \mathrm{~N}$ and the cohesive radius is 0.5 times the unit radius.

The performance parameters of $\mathrm{Al}$ alloy unit: the normal stiffness is $8 \mathrm{Gpa}$, the tangential stiffness is $8 \mathrm{Gpa}$, the normal and tangential bond strengths are $3000 \mathrm{~N}$ and the cohesive radius is 0.5 times the unit radius.

The property parameters of the interface between $\mathrm{SiC}$ particles and $\mathrm{Al}$ alloy are similar with $\mathrm{Al}$ alloy.

Boundary conditions: the load on the both ends of the long axis of the specimen is gradually exerted by $10 \mathrm{~N}$ load every 1000 time step until damage of the specimen.

\subsection{Simulation of the distribution of contact force during loading process}

The contact force among discrete elements is an important parameter of the micro-model used in the paper, which can reflect the mechanical properties of the composite from the microscopic view. From Figures 6 and 7, it can be seen that the contact pressure appears the partial focus phenomenon, while the distribution of the contact tension tends to increase. When the calculation loop reaches 170,000 time steps (Figure 8), all the focus areas of contact pressure almost connected, but the contact tension is almost unchanged. At this time, the material closes to destruction. When the calculation loop reaches 210,000 time steps (Figure 9), the contact pressure tends to uniformity, but the distribution of contact tension becomes sparser. The reason is that due to material damage the bonding between the contacts is destroyed. Therefore, the contacts between the discrete units are approximately scattered and the contact tension is close to zero and the contact pressure is evenly even-distributed.

Similarly to the case of annealing heat treatments, when a material containing residual stresses is deformed, internal stresses opposite to the applied stress can relax following a exponential decay as deformation progresses. This phenomenon has been extensively studied during the last decade. It is well establish that during early stages of plastic deformation, typically below $2 \%$, the initial residual stresses are almost totally relaxed. After this initial stage the stress relaxation become less pronounced, like in the case of annealing. However, after some degree of cumulative deformation, the internal structure of the material is changed by dislocation multiplication, forest dislocations, subgrains, etc. imposing new strain gradients increasing the general residual stress level (Requena et al., 2012). The deviatoric component relaxes completely after a certain value of deformation, while the hydrostatic component increases due to the new plastic strain gradients (Fernández et al., 2005; Jing and Stephansson, 2014). The relaxation behaviour of a conventional unreinforced $2024 \mathrm{IM} \mathrm{Al}$ alloy is shown for comparison. It is shown that the presence of reinforcement particles, introduce a higher residual stress level and a higher increase of the hydrostatic component progressing with deformation, mainly due to microstresses induced by geometrical necessary dislocations. 


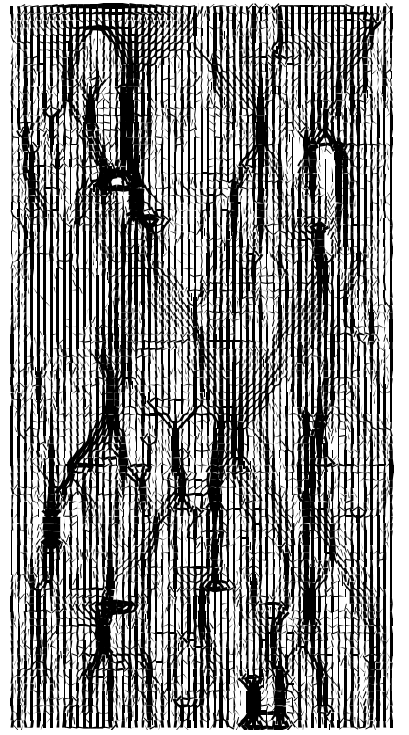

(a) Distribution of contact pressure Figure 6. Distribution of contact pressure and tension stress at the 46000th step

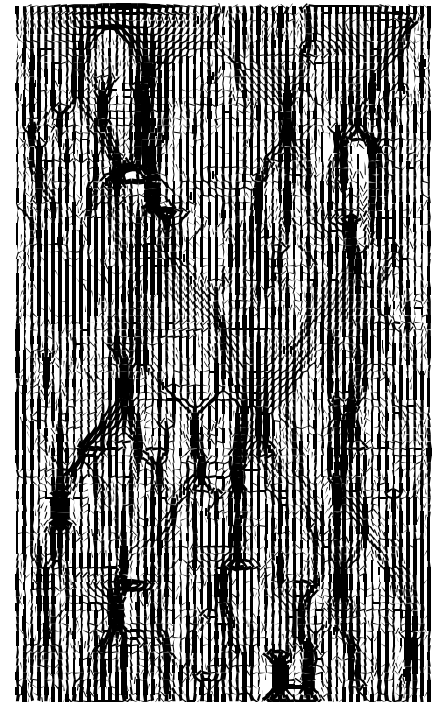

(a) Distribution of contact pressure Figure 7. Distribution of contact pressure and tension stress at the 11000th step

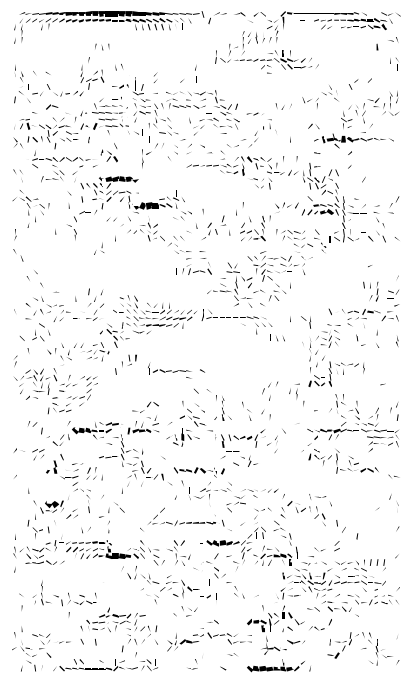

(b) Distribution of contact tension 


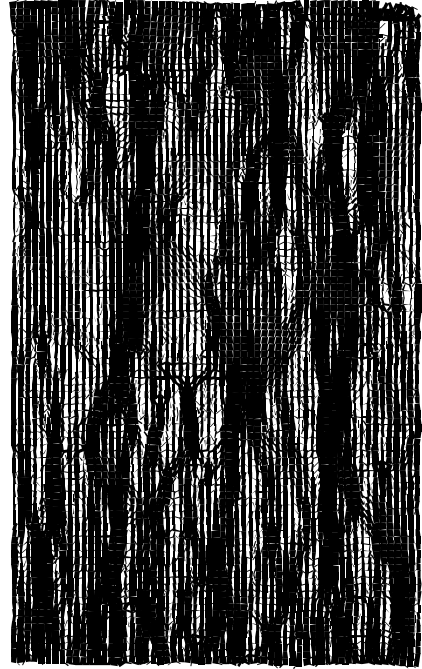

(a) Distribution of contact pressure

Figure 8. Distribution of contact pressure and tension stress at the 170000th step

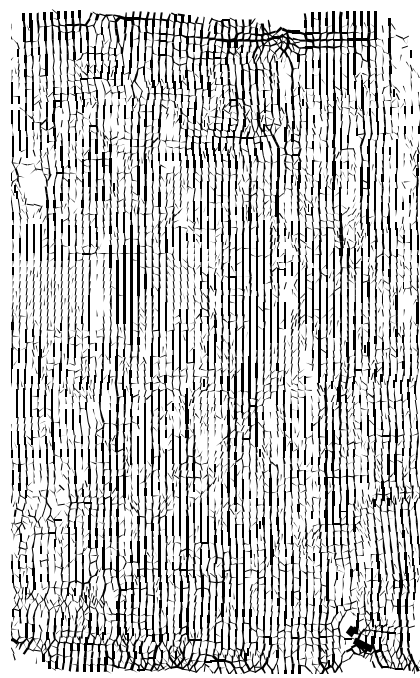

(a) Distribution of contact pressure

Figure 9. Distribution of contact pressure and tension stress at the 210000th step

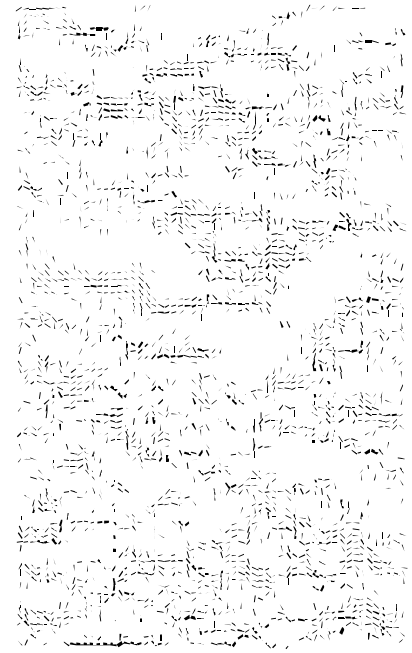

(b) Distribution of contact tension

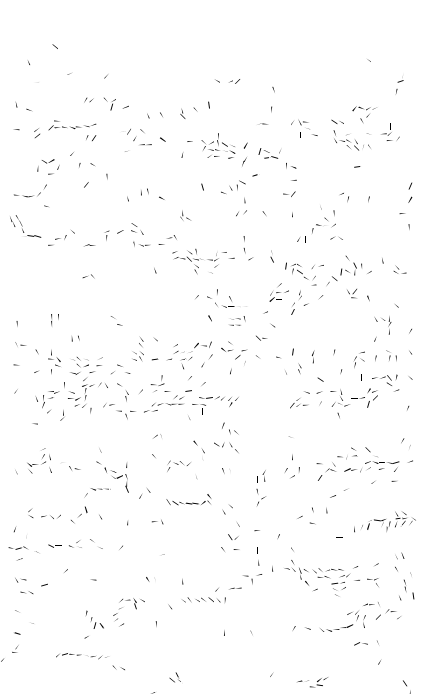

(b) Distribution of contact tension

\section{Conclusion}

Based on the full consideration of the properties of each phase materials, the micro-view two-dimensional numerical model of $\mathrm{SiC} / \mathrm{Al}$-matrix composite microstructure is established by discrete element method, which is close to the actual situation. Simulation of the sizes and distributions of contact pressure and tension from small load to big load until destruction was carried out. The results showed that the contact pressure appears the partial focus phenomenon, while the distribution of the contact tension tends to increase. When the calculation loop reaches 170,000 time steps, all the focus areas of contact pressure almost connected, but the contact tension is almost unchanged. At this time, the material closes to destruction. When the calculation loop reaches 210,000 time steps, the contact pressure tends to uniformity, but the distribution of contact tension becomes sparser. The contacts between the discrete units are approximately scattered and the contact tension is close to zero and the contact pressure is evenly even-distributed. 


\section{Acknowledgements}

We thank Science and Technology Plan of Shenzhen that give us the financial support (grant nos. JCYJ20140418100633644 and JCYJ20160415114050831).

\section{References}

Chong L., Shusen W., Jinbiao Z., Ping A.; Li W., 2013, Combined effects of ultrasonic vibration and manganese on Fe-containing inter-metallic compounds and mechanical properties of Al-17Si alloy with 3wt.\%Fe, China Foundry, Vol. 10, No. 3, pp. 89-96.

Chen X., Geng H.-Y., Li. Y.-X., 2005, Assessment of modification level of hypoeutectic Al-Si alloys by pattern recognition of cooling curves, China Foundry, Vol. 2, No. 4, pp. 246-253.

Djordjevic N., 2003, Discrete element modelling of lifter stresses in tumbling mill, Transactions of the Institution of Mining and Metallurgy Section C- Mineral Processing and Extractive Metallurgy, Vol. 112, No. 2, pp. 115-119.

Fernández, P., Fernández, R., González-Doncel, G. and Bruno, G., 2005, Correlation between matrix residual stress and composite yield strength in PM 6061 Al-15 vol\% SiCw. Scripta Materialia, Vol. 52, No. 8, pp. 793-797.

Hu H., Zhang W., Hu H., 1998, Formation mechanism of interfacial reaction layer in SiCp/ZA 22 composites, Acta Materiae Compositae Sinica, Vol. 15, No. 2, pp. 27-30.

Jing L., Stephansson O., 2014, Implicit discrete element method for block systems - discontinuous deformation analysis (DDA), Engineering Geology, Vol. 49, No. (3-4), pp. 371-381.

Liu B., Liu X., Liu M., Zhao Z., 2011, Infiltration mechanism in SiCp/aluminum-matrix composite prepared by non-pressure, Materials and Manufacturing Processes, Vol. 26, No. 11, pp. 1339-1345.

Liu B., Liu L. R., Liu X. J. 2013, Effects of carbon nanotubes on crystallization in amorphous Ni-P electroplating coating, Surface Engineering, Vol. 29, No. 3, pp. 190-193.

Liu B., Liu L. 2013, Interfaces between carbon nanotubes and nickel nanoparticles in carbon nanotubes, Functional Materials Letters, Vol. 6, No. 6, 1350056 (4 p.).

Liu B., Liu L., Zhao Z. 2014. Molecular dynamics simulation for arrangement of nickel atoms filled in carbon nanotubes, Journal of Applied Physics, Vol. 116, No. 8, 084305.

Requena G., Garcés G., Fernández R. and Schöbel M., 2012, Determination of internal stresses in lightweight metal matrix composites, www.intechopen.com, 14 Mar 2012, pp. 277-281.

Wang G., Qin J., 2007, Numerical simulation of mechanical behaviors of ellipsoid granular materials by discrete element method, Journal of Dalian University, Vol. 28, No. 6, pp. 27-31.

$\mathrm{Xi}-\mathrm{Ya} \mathrm{Z} ., 2$ 2004, The microstructures and properties of $\mathrm{SiC} / \mathrm{Al}_{2} \mathrm{O}_{3} / \mathrm{Al}-\mathrm{Si}$ composites prepared by reactive penetration, Journal of Wuhan University of Technology-Material Science Edition, Vol. 19, No. 3, pp. 45-47.

You Z., 2003, Development of a micromechanical modeling approach to predict asphalt mixture stiffness using the discrete element method, Ph.D. Dissertation, Department of Civil Engineering, Urbana-Champaign: University of Illnois, USA.

Zhao L., Cao X., Tian C. 2006, Solidification structure of squeeze casting SiC/Al Alloy ZL $\mathrm{L}_{109}$ co-continuous composites, Acta Metallurgica Sinica, Vol. 42, No. 3, pp. 325-330.

Zhang S.-Q., Cui Y., Wang M.-X., Song Y.-G. 2001, Investigation on reaction mechanism of SiC particulate reinforced aluminum matrix composite prepared by pressureless infiltration, Journal of Materials Engineering, Vol. 12, pp. 8-11.

\section{Biographical notes}

Liu Bai, Xiaohong Yang, Zhenyu Zhao are from Shenzhem Institute of Information Technology, Shenzhen, 518172, P.R.China

Received May 2016

Accepted May 2016

Final acceptance in revised form October 2016 